\title{
Profil Asupan Minum pada Anak Prasekolah di Daerah Urban dan Rural di Indonesia dan Faktor-faktor yang Memengaruhinya
}

Titis Prawitasari, Bernie E. Medise, Diana Sunardi, Dewi Friska, Erfi Prafiantini, Rizki Y. Pohan, Budi Wiweko

Indonesian Hydration Working Group, Fakultas Kedokteran Universitas Indonesia, Jakarta

Latar belakang. Asupan minum y ang ku rang akan berdampak terhadap performa fisik dan kognitif serta dapat menimbulkan manifestasi klinis, seperti pusing, lesu, dan gangguan konsentrasi. Anak memiliki proporsi cairan tubuh yang lebih tinggi dibandingkan dewasa. Hingga saat ini belum ada data mengenai kecukupan asupan minum anak prasekolah di Indonesia.

Tujuan. Mengetahui kecukupan asupan minum anak prasekolah di daerah urban dan rural di Indonesia.

Metode. Penelitian dengan desain potong lintang dilakukan pada bulan Januari-Maret 2016 di Jakarta dan Maluku pada anak usia 36-72 bulan. Perhitungan jumlah cairan dilakukan dengan mencatat jumlah yang diminum dalam 7 Day-Fluid Diary Record. Asupan minum total ditentukan berdasarkan jumlah yang dikonsumsi dari semua kategori dan sesuai dengan angka kecukupan gizi (AKG) 2019.

Hasil. Sebanyak 585 anak mengikuti penelitian ini dengan median asupan minum adalah $1133,1(85-2991,4) \mathrm{mL} / \mathrm{hari}$ dan jenis asupan paling tinggi adalah air putih. Subjek yang tinggal di daerah urban mempunyai faktor risiko lebih rendah untuk mengalami asupan minum yang kurang ( $\mathrm{RR}=0,580 ; 95 \% \mathrm{IK}$ : 0,418-0,807; $\mathrm{p}=0,001)$. Demikian pula semakin muda usia subjek, maka semakin kecil kemungkinan untuk mengalami kejadian asupan minum yang kurang ( $\mathrm{RR}=0,497 ; 95 \% \mathrm{IK}$ : 0,356-0,694; $\mathrm{p}=0$,000). Kesimpulan. Rerata asupan minum anak usia prasekolah di Indonesia sedikit lebih rendah dari anjuran AKG. Anak prasekolah berusia $\geq 54$ bulan dan anak yang tinggal di area rural lebih berisiko mengalami kekurangan asupan minum. Sari Pediatri 2020;22(4):236-42

Kata kunci: asupan minum, urban, rural, prasekolah

\section{Profile of Fluid Intake of Pre-School Children in Urban and Rural Areas in Indonesia and the Affecting Factors}

Titis Prawitasari, Bernie E. Medise, Diana Sunardi, Dewi Friska, Erfi Prafiantini, Rizki Y. Pohan, Budi Wiweko

Background. Inadequate fluid intake affects both physical and cognitive performance, as well as clinical manifestations such as headache, sluggishness, lowered concentration. Children have a higher proportion of body fluids than adults. Currently, there is no data regarding the adequacy of water intake among pre-school children in Indonesia.

Objective. The purpose of this study was to observe the adequacy of fluid intake among pre-school children in urban and rural areas in Indonesia.

Methods. A cross-sectional study was conducted from January to March 2016 in Jakarta and Maluku among 36-72 months aged children. Seven Days Fluid Diary Record was utilized to obtain the data of participants' fluid intake. The total fluid intake is determined by the amount consumed from all categories and according to Indonesia Recommended Dietary Allowance (RDA) 2019.

Result. There were 585 children included in this study. The median fluid intake was $1133.1(85-2991.4) \mathrm{mL} / \mathrm{day}$ with the highest contribution was plain water. Subjects living in urban areas had lower risk for drinking inadequately $(\mathrm{RR}=0.580$; $95 \% \mathrm{CI}$ : $0.418-$ $0.807 ; \mathrm{p}=0.001)$, as well as the younger subjects, they less likely to experience inadequate fluid intake (RR=0.497; 95\%CI: 0.356-0.694; $\mathrm{p}=0.000)$.

Conclusion. The median fluid intake of pre-school children in Indonesia was slightly lower than the RDA. Children older than 54 months and live in rural area have a higher risk of inadequate fluid intake. Sari Pediatri 2020;22(4):236-42

Keywords: drinking intake, urban, rural, preschool children

Alamat korespondensi: Titis Prawitasari. Fakultas Kedokteran Universitas Indonesia, Jakarta. Jl Salemba Raya Jakarta Pusat. Email: tprawitasari@yahoo.com 
$\mathrm{T}$ Yubuh memerlukan cairan untuk hidup, yaitu sebagai pembentuk sel dan cairan tubuh, pengatur suhu tubuh, pelarut, pelumas dan bantalan, media transportasi dan eliminasi sisa metabolisme. Tubuh tidak dapat memenuhi seluruh kebutuhannya akan air. Oleh karena itu, kebutuhan tubuh akan air perlu dipenuhi oleh manusia dengan asupan air yang cukup. ${ }^{1}$ Fungsi fisiologis dari keseimbangan cairan pada anak, seperti pematangan fungsi ginjal terjadi sekitar usia 2 tahun, serta rasio permukaan tubuh yang lebih tinggi dibandingkan massa tubuh menunjukkan kehilangan cairan yang tidak disadari melalui kulit. Hal ini menjelaskan mengapa anak memiliki kebutuhan cairan yang lebih tinggi dibandingkan dengan massa tubuhnya juga ketika dibandingkan dengan orang dewasa. ${ }^{2}$ Selain perbedaan fisiologis, air juga menjadi komponen penting untuk kebiasaan minum sehat yang berkelanjutan pada anak. Anak yang terbiasa minum air sedikit, juga akan menjadi orang dewasa dengan kebiasaan minum air yang juga sedikit sehingga kemungkinan akan memberikan konsekuensi pada ginjal ${ }^{2,3}$ kondisi metabolik, ${ }^{4,5}$ serta memengaruhi performa fisik, ${ }^{6}$ kognitif, dan mood. ${ }^{2,7}$ Survei asupan minum di daerah urban dan rural. Oleh karena itu, studi ini bertujuan untuk mendapatkan data mengenai jumlah asupan minum total harian pada anak prasekolah di daerah urban dan rural di Indonesia serta faktor-faktor yang memengaruhinya.

\section{Metode}

Penelitian ini merupakan studi potong lintang yang dilaksanakan pada bulan Januari sampai Maret 2016 di Jakarta dan Maluku. Jakarta dan Maluku dipilih sebagai representasi daerah urban dan rural di Indonesia serta untuk mewakili wilayah Indonesia bagian barat dan bagian timur. Iklim dan suhu harian yang sedikit berbeda juga menjadi salah satu pertimbangan dalam pemilihan area ini. Demikian pula dengan perbedaan dalam hal akses air minum yang bersih dan aman untuk komunitasnya yang sangat mungkin berbeda karena perbedaan faktor sosial ekonomi. Selain itu, perbedaan wilayah daratan dan kepulauan serta pembangunan wilayah barat dan timur Indonesia merupakan ${ }^{12,13}$ beberapa negara pada anak sehat mendapatkan adanya kecenderungan konsumsi jumlah cairan yang tidak memadai sehingga dapat mengakibatkan dehidrasi berkelanjutan..$^{8-10}$ Asupan minum yang tidak memadai pada anak dapat memberikan manifestasi klinis pusing, lesu, gangguan konsentrasi dan penurunan fungsi kognitif. Bahkan, dehidrasi lebih lanjut juga dapat menyebabkan penurunan aktivitas saraf simpatik serta gangguan termoregulasi tubuh. ${ }^{10}$ Masalah ini penting untuk dicermati, karena terdapat studi yang membuktikan korelasi antara asupan minum yang rendah dengan risiko gangguan kesehatan dan perkembangan. ${ }^{11}$

Hingga saat ini masih terbatas penelitian mengenai jumlah asupan minum anak Indonesia. Laksmi $\mathrm{dkk}^{12}$ melakukan studi pada populasi Indonesia dengan rentang usia 4-65 tahun. Laksmi $\mathrm{dkk}^{12}$ mendapatkan bahwa proporsi anak usia 4-9 tahun yang tinggal di Jabodetabek memenuhi rekomendasi asupan Indonesia yang memadai. Namun, data mengenai jumlah asupan pada anak dengan usia yang lebih muda, khususnya usia prasekolah (2-6 tahun) belum ada. Demikian pula data yang membandingkannya dengan faktor yang perlu diperhitungkan.

Subjek penelitian merupakan anak berusia 36-72 bulan yang terdaftar di PAUD di Jakarta dan Maluku. Pemilihan subjek dilakukan dengan stratified random sampling di PAUD pada area yang dipilih untuk merekrut sampel yang memenuhi syarat. Kriteria inklusi dalam penelitian ini adalah anak berusia antara 36-72 bulan yang bersedia untuk berpartisipasi, dengan kriteria eksklusi yaitu anak yang sedang sakit atau butuh perawatan kesehatan khusus, pengasuhnya tidak dapat berkomunikasi dengan baik atau menolak untuk bergabung.

Ethical clearence diperoleh dari Komite Etik Fakultas Kedokteran Universitas Indonesia nomor 727/UN2.F1/ETK/2016. Perizinan dari pemerintah daerah serta ototritas kesehatan setempat diminta sebelum melakukan penelitian. terdaftar dalam penelitian ini

\section{Karakteristik umum}

Karakteristik sosio-demografi responden dikumpulkan menggunakan kuesioner yang telah divalidasi, yang terdiri dari usia, jenis kelamin, usia orangtua/ pengasuh, tingkat pendidikan, dan pengeluaran keluarga dalam sebulan. 


\section{Asupan minum}

Perhitungan jumlah asupan cairan dilakukan dengan mencatat jumlah yang diminum dalam buku harian (7 Day-Fluid Diary Record - 7D- FLDR). Enumerator dilatih untuk menyampaikan dan menjelaskan kepada responden tentang cara mengisi catatan selama 7 hari serta akan mengkaji pencatatan yang dilakukan orang tua atau pengasuh terhadap volume dan jenis minuman yang dikonsumsi anak mereka selama 7 hari berturut-turut. Jumlah konsumsi minuman itu tetap kosong untuk diisi oleh enumerator. Untuk memastikan kelengkapan pencatatan dan meminimalisasi bias, enumerator mengevaluasi dan mengambil record yang telah diisi setiap hari. Setelah isian record diambil, mereka harus mengubah kode dalam formulir record menjadi volume minuman yang dikonsumsi dalam mililiter $(\mathrm{mL})$. Pencatatan yang dilakukan meliputi informasi terperinci tentang tindakan minum, seperti waktu minum, jenis minuman, merek minuman, jumlah penyajian yang dikonsumsi, dan lokasi di mana tindakan minum itu terjadi. Buku foto porsi minum disediakan untuk responden dalam membantu mereka memperkirakan jumlah asupan minum.

Semua cairan yang telah dicatat diklasifikasikan sebagai air putih; susu sapi dan turunannya; jus buah $100 \%$; minuman manis termasuk minuman ringan berkarbonasi, kopi atau teh siap minum; minuman panas (kopi dan teh); dan minuman lainnya (susu kedelai, minuman herbal, dessert ice seperti es cendol, es krim). Asupan minum total ditentukan oleh jumlah yang dikonsumsi dari semua kategori dan sesuai dengan angka kecukupan gizi (AKG Indonesia) berdasarkan kelompok umur dan jenis kelamin, yang dikeluarkan oleh Kementerian Kesehatan Republik Indonesia tahun 2019. Angka yang tercantum dalam AKG tersebut juga memperhitungkan jumlah cairan dalam makanan, sedangkan dalam penelitian ini hanya memperhitungkan jumlah asupan minum dari minuman saja sehingga dilakukan pengurangan sebanyak $20 \%$ dari yang tercantum dalam AKG tersebut sebagai jumlah cairan yang berasal dari makanan, seperti dilakukan pada penelitian lainnya. ${ }^{12,14} \mathrm{Pada}$ penelitian ini, usia 54 bulan diambil nilai tengah usia prasekolah/PAUD. Pada anak dengan usia $<54$ bulan dikategorikan sebagai anak dengan asupan minum rendah jika mengonsumsi lebih rendah dari
$920 \mathrm{~mL} /$ hari, sedangkan untuk anak usia $\geq 54$ bulan, dikelompokkan ke dalam asupan minum rendah jika mengkonsumsi di bawah $1160 \mathrm{~mL} / \mathrm{hari}$.

\section{Analisis statistik}

Analisis Statistik dilakukan dengan menggunakan IBM SPSS Statistics untuk Windows versi 16.00. Uji normalitas distribusi data dilakukan menggunakan Kolmogorov- Smirnoff. Univariat digunakan untuk menyajikan karakteristik subjek berdasarkan urban dan rural di antara anak prasekolah. Status asupan minum total dijabarkan dengan jenis minuman. Analisis bivariat dilakukan menggunakan chi-square untuk menentukan hubungan asupan minum cukup dan kurang dengan karakteristik subjek. Semua data dianalisis dengan confidence interval 95\% dan nilai p kurang dari 0,05 akan dikatakan signifikan secara statistik.

\section{Hasil}

Pada penelitian ini, diperoleh total 585 anak yang terdiri dari 287 anak di Jakarta dan 298 anak di Maluku yang termasuk ke dalam kriteria inklusi. Terdapat 5 kecamatan pada tiap daerah yang diikutsertakan. Gambaran karakteristik subjek penelitian tertera pada Tabel 1 .

Berdasarkan data Tabel 1, subjek di daerah urban lebih banyak yang berusia lebih muda (66,2\%), dibanding dengan subjek yang berasal dari daerah rural $(33,8 \%)$. Anak prasekolah yang berada di daerah urban lebih banyak diasuh oleh ibu, sedangkan untuk pengasuh selain ibu lebih banyak dialami anak yang tinggal di daerah rural. Pengeluaran rumah tangga dalam 1 bulan terakhir dengan kategori di atas upah minimum regional (UMR), lebih banyak terjadi pada subjek yang tinggal di daerah rural.

Pada Tabel 2, median total asupan minum pada subjek yang tinggal di daerah urban dan rural adalah masing-masing 1182,9 $(354,6-2991,4) \mathrm{mL} /$ hari dan 1089,3 (85-2987,5) mL/hari. Jika diuraikan lebih rinci lagi, subjek di daerah urban dan rural mengonsumsi air putih dalam kisaran yang tidak jauh berbeda, yaitu 577,9 (32,1-2420,1) $\mathrm{mL} /$ hari untuk subjek daerah urban dan 597,4 (33,39-2517,5) mL/ hari untuk yang berada di daerah rural. 
Tabel 1. Karakteristik subjek penelitian

\begin{tabular}{lcc}
\hline Variabel & Urban $\mathrm{n}(\%)$ & Rural $\mathrm{n}(\%)$ \\
\hline Usia anak (bulan) & & \\
$\quad<54$ & $180(66,2)$ & $92(33,8)$ \\
$\geq 54$ & $107(34,2)$ & $206(65,8)$ \\
Jenis kelamin & & \\
$\quad$ Laki-laki & $139(51,7)$ & $130(48,3)$ \\
$\quad$ Perempuan & $138(46,8)$ & $168(53,2)$ \\
Pengasuh & & \\
$\quad$ Ibu & $241(52,5)$ & $218(47,5)$ \\
$\quad$ Lainnya & $46(36,5)$ & $80(63,5)$ \\
Pendidikan pengasuh (tahun) & & $50(36,2)$ \\
$\quad<12$ & $88(63,8)$ & $248(55,5)$ \\
$\quad \geq 12$ & $199(44,5)$ & $267(49,5)$ \\
Jumlah anak dibawah 5 tahun & & $31(67,4)$ \\
$\quad 1$ & $272(50,5)$ & $144(59,3)$ \\
$\quad \geq 1$ & $15(32,6)$ & $154(45)$ \\
Pengeluaran 1 bulan terakhir & & \\
$\quad>$ UMR & $99(40,7)$ & \\
$\quad \leq$ UMR & $188(55)$ & \\
\hline
\end{tabular}

Tabel 2. Asupan minum anak berdasarkan jenis cairan dan area penelitian

\begin{tabular}{|c|c|c|c|}
\hline Variabel & $\begin{array}{c}\text { Urban } \\
\text { (Median (Min-Maks)) }\end{array}$ & $\begin{array}{c}\text { Rural } \\
\text { (Median (Min-Maks)) }\end{array}$ & $\begin{array}{c}\text { Total } \\
\text { (Median (Min-Maks)) }\end{array}$ \\
\hline Asupan minum total (ml/hari) & $1182,9(354,6-2991,4)$ & $1089,3(85-2987,5)$ & $1133,1(85-2991,4)$ \\
\hline Air putih & $577,9(32,1-2420,1)$ & $597,4(33,39-2517,5)$ & $582,5(32,1-2517,5)$ \\
\hline Susu sapi & $420,5(0-1922,1)$ & $196,9(0-1582,86)$ & $304,3(0-1922,1)$ \\
\hline Jus buah & $0(0-173,9)$ & $0(0-227,7)$ & $0(0-227,7)$ \\
\hline Sweet sugar beverage (SSB) & $3(0-490,2)$ & $0(0-350)$ & $0(0-490,2)$ \\
\hline Minuman panas & $60,5(0-751,5)$ & $70,8(0-743,2)$ & $65,2(0-751,5)$ \\
\hline Lainnya* & $0(0-379,3)$ & $0(0-117,9)$ & $0(0-379,29)$ \\
\hline
\end{tabular}

${ }^{*}$ Lainnya adalah: susu kedelai, minuman herbal, dessert ice

Median asupan susu pada subjek yang berada di daerah urban lebih tinggi dibandingkan asupan yang dikonsumsi subjek pada daerah rural $(420,5$ (0-1922,1) vs $196,9(0-1582,86) \mathrm{mL} / \mathrm{hari})$.

Hanya sedikit subjek yang mempunyai kebiasaan mengonsumsi jus buah pada daerah urban dan rural $(0(0-173,9)$ vs $0(0-227,7)) \mathrm{mL} /$ hari. Demikian pula terjadi pada minuman manis (Sweet Sugar Beverage= $S S B)$, yaitu $3(0-490,2)$ vs $0(0-350) \mathrm{mL} /$ hari. Subjek yang tinggal di daerah rural, mengonsumsi minuman panas yang lebih tinggi dibandingkan dengan yang tinggal di daerah urban $(70,8(0-743,2) \mathrm{mL} /$ hari $)$ vs $60,5(0-751,5)$.
Berdasarkan Tabel 3, terlihat bahwa Subjek yang tinggal di daerah urban memiliki faktor protektif terhadap asupan minum kurang $(\mathrm{RR}=0,580 ; 95 \%$ IK: 0,418-0,807; $\mathrm{p}=0,001)$. Demikian pula usia $<54$ bulan, merupakan faktor protektif terhadap kejadian asupan minum yang kurang $(\mathrm{RR}=0,497 ; 95 \% \mathrm{IK}$ : $0,356-0,694 ; \mathrm{p}=0,000)$.

\section{Pembahasan}

Penelitian ini memilih kota Jakarta sebagai daerah yang mewakili urban karena memiliki kepadatan 
Titis Prawitasari dkk: Profil asupan minum pada anak prasekolah di daerah urban dan rural

Tabel 3. Kecukupan asupan minum

\begin{tabular}{|c|c|c|c|c|c|}
\hline Variabel & Asupan & minum kurang (\%) & Asupan minum cukup (\%) & $\mathrm{RR}$ & $\mathrm{P}$ \\
\hline \multicolumn{6}{|l|}{ Area penelitian } \\
\hline Urban & & $109(38,0)$ & $178(62,0)$ & 0,580 & $0,001^{*}$ \\
\hline Rural & & $153(51,3)$ & $145(48,7)$ & & \\
\hline \multicolumn{6}{|c|}{ Usia anak (bulan) } \\
\hline$<54$ & & $97(35,7)$ & $175(64,3)$ & 0,497 & $0,000^{*}$ \\
\hline$\geq 54$ & & $165(52,7)$ & $148(47,3)$ & & \\
\hline \multicolumn{6}{|l|}{ Jenis kelamin } \\
\hline Laki-laki & & $118(43,9)$ & $151(56,1)$ & 0,933 & 0,680 \\
\hline Perempuan & & $144(45,6)$ & $172(54,4)$ & & \\
\hline \multicolumn{6}{|l|}{ Pengasuh } \\
\hline Ibu & & $212(46,2)$ & $247(53,8)$ & 1,305 & 0,193 \\
\hline Lainnya & & $50(39,7)$ & $76(60,3)$ & & \\
\hline \multicolumn{6}{|c|}{ Pendidikan pengasuh (tahun) } \\
\hline$<12$ & & $62(44,9)$ & $76(55,1)$ & 1,008 & 0,970 \\
\hline$\geq 12$ & & $200(44,7)$ & $247(55,3)$ & & \\
\hline \multicolumn{6}{|c|}{ Jumlah anak di bawah 5 tahun } \\
\hline 1 & & $245(45,5)$ & $294(54,5)$ & 1,422 & 0,266 \\
\hline$>1$ & & $17(37,0)$ & $29(63,0)$ & & \\
\hline \multicolumn{6}{|c|}{ Pengeluaran 1 bulan terakhir } \\
\hline$\geq \mathrm{UMR}$ & & $108(44,4)$ & $135(55,6)$ & 0,977 & 0,889 \\
\hline$<\mathrm{UMR}$ & & $154(45,0)$ & $188(55,0)$ & & \\
\hline
\end{tabular}

penduduk tertinggi di Indonesia, yaitu 15.366,87/ $\mathrm{km}^{2}$ berdasarkan Badan Pusat Statistik Provinsi DKI Jakarta tahun 2015. ${ }^{15}$ Selain itu, Jakarta juga mewakili daerah Indonesia Barat. Maluku dipilih sebagai area yang mewakili rural karena Maluku memiliki daerah pedesaan berbukit yang juga memiliki area pantai dengan kepadatan penduduk $26,79 / \mathrm{km}^{2},{ }^{16,17}$ serta mewakili daerah Indonesia Timur. Iklim dan suhu harian yang sedikit berbeda juga menjadi salah satu pertimbangan dalam pemilihan area ini. Demikian pula dengan perbedaan dalam hal akses air minum yang bersih dan aman untuk komunitasnya yang sangat mungkin berbeda karena perbedaan faktor sosial ekonomi. Kemudian, perbedaan wilayah daratan dan kepulauan serta pembangunan wilayah barat dan timur Indonesia merupakan faktor yang perlu diperhitungkan. ${ }^{12,13}$

Berdasarkan penelitian ini, rerata asupan minum pada anak berusia 36-72 bulan di Indonesia berkisar 1133,1 (85-2991,4) $\mathrm{mL} /$ hari. Jumlah ini sedikit lebih rendah dari jumlah yang direkomendasikan oleh Kementerian Kesehatan Republik Indonesia (AKG Indonesia) untuk anak usia 1-3 tahun, yaitu
$1150 \mathrm{~mL}$ dan anak usia 4-6 tahun sebesar 1450 ml. ${ }^{18}$ Namun, perlu diingat bahwa total asupan minum yang dicatat tidak memperhitungkan 20\% cairan yang berasal atau terkandung dalam makanan. Jumlah $1133 \mathrm{~mL}$ untuk anak usia 3-6 tahun yang menjadi subjek penelitian ini masih dalam batas yang direkomendasikan. ${ }^{12}$ Terdapat $52,7 \%$ untuk usia $\geq 54$ bulan yang termasuk dalam kategori asupan minum rendah. Hasil penelitian ini sedikit berbeda dengan penelitian oleh Laksmi $\mathrm{dkk}^{12}$ yang mendapatkan 78\% anak Indonesia usia 4-9 tahun memenuhi volume yang direkomendasikan oleh AKG Indonesia. ${ }^{18}$ Perbedaan ini kemungkinan terjadi karena adanya perbedaan kisaran usia serta tidak membedakan daerah urban dan rural.

Berkenaan dengan jenis minuman yang dikonsumsi oleh anak prasekolah, memperlihatkan hasil yang menyerupai penelitian Drewnowski ${ }^{4}$ dan Laksmi, ${ }^{12}$ yaitu bahwa air putih memberikan kontribusi terbesar terhadap total asupan minum per harinya dan minuman berbasis susu sebagai jenis minuman terbesar kedua yang dikonsumsi oleh anak prasekolah., Kondisi ini terutama terlihat lebih nyata pada daerah 
urban. Anak yang mengonsumsi susu lebih banyak dapat menurunkan konsumsi SSB karena mengganti SSB dengan air, kopi/teh, susu atau 100\% jus buah. ${ }^{4}$

Penelitian ini juga menemukan bahwa subjek di daerah urban relatif lebih muda dan diasuh sendiri oleh ibunya. Hal ini tentunya berdampak terhadap kemungkinan tercukupinya kebutuhan minum subjek yang berada di daerah urban karena diasuh sendiri oleh ibunya. Mengingat semakin muda usia anak, semakin besar peran ibu/pengasuh dalam menentukan jumlah dan jenis makanan dan minuman demi kecukupannya setiap hari. ${ }^{2,20}$ Usia dan jenis kelamin anak memiliki peran yang signifikan dalam jumlah total, jenis, dan proporsi relatif dari minuman yang dikonsumsi oleh anak. ${ }^{21}$ Pada penelitian ini juga didapatkan bahwa semakin bertambah usia anak, terbukti memiliki risiko untuk mengalami ketidakcukupan asupan minum. Hal ini dapat dijelaskan bahwa pada anak yang sangat muda, ketersediaan minuman dan makanan masih sangat tergantung pada orang dewasa. ${ }^{2,5}$ Pada usia prasekolah, perilaku seperti gaya hidup sehat dan pola makan mulai berkembang dan sebagian besar dipengaruhi oleh keluarga dan jumlah anak. ${ }^{22}$ Kebiasaan minum pada anak diharapkan dapat dipertahankan sepanjang hidup. Anak yang mempunyai kebiasaan minum air sedikit akan menjadi orang dewasa dengan kebiasaan yang sama sehingga memiliki konsekuensi pada ginjal ${ }^{2,3}$ dan kondisi metabolik ${ }^{4,5}$ serta memengaruhi kinerja fisik, ${ }^{6}$ kognitif, dan mood. ${ }^{2,7}$ Oleh karenanya, penting untuk melibatkan seluruh komponen lingkungan di sekitar anak, baik orangtua, guru maupun teman agar terbentuk perilaku makan dan minum yang baik. Tidak lupa pula ketersediaan fasilitas air bersih dan air bersih di lingkungan rumah dan sekolah dapat turut membantu terciptanya kebiasan minum yang sehat.

Asupan minum anak daerah urban lebih banyak tercukupi, sedangkan pada daerah rural jumlah anak yang cukup maupun kurang asupan minumnya memiliki jumlah hampir sama. ${ }^{22} \mathrm{Hal}$ ini dapat terjadi karena perbedaan geografis antar pulau tempat tinggal dan antara daerah urban dan rural sehingga rumah tangga yang tinggal di daerah urban lebih cenderung memiliki akses ke sumber air yang lebih baik. ${ }^{23,24}$ Selain itu, pada penelitian mengungkapkan sekitar 93\% penduduk urban memiliki akses ke sumber air yang lebih baik dibandingkan dengan $76 \%$ di daerah rural. ${ }^{23}$ Akses air pada daerah urban telah lebih baik dan jumlahnya meningkat pesat, sedangkan di daerah rural masih harus ditambah dan diperbaiki. ${ }^{25}$ Perlu adanya perluasan layanan air bersih melalui pipa, memastikan pasokan air untuk masyarakat dalam jangka pendek harus diutamakan untuk menyediakan air minum yang aman. ${ }^{12}$

Pada penelitian ini juga didapatkan bahwa tidak terdapat perbedaan dalam hal jumlah pengeluaran pendapatan pada daerah urban dan rural, tetapi proporsi anak dengan asupan minum yang kurang lebih banyak pada daerah rural. Dibanding dengan angka pengeluaran nasional, rerata angka pengeluaran pada kedua daerah penelitian masih harus ditingkatkan, sehingga hal ini dapat menjadi salah satu faktor yang memengaruhi ketersediaan air minum yang layak, di samping juga faktor ketidaktahuan maupun geografis. Perbedaan status sosial ekonomi individu telah terbukti memengaruhi risiko dehidrasi dalam masyarakat. ${ }^{12}$ Status sosial ekonomi dikaitkan dengan perbedaan akses menuju air bersih dan atau air keran. ${ }^{13}$ Selain itu, harus diakui bahwa status sosial ekonomi dapat memengaruhi akses air minum yang aman dan kemampuan untuk membeli air kemasan. ${ }^{12}$ Faktor iklim serta perbedaan suhu dan kelembaban antara kedua daerah tampaknya kurang berperan dalam memengaruhi jumlah asupan. Ketersediaan air bersih dan air minum merupakan faktor yang lebih berperan untuk memperbaiki mengurangi jumlah anak dengan asupan minum yang rendah.

\section{Kesimpulan}

Rerata asupan minum anak usia prasekolah di Indonesia sedikit lebih rendah dari anjuran AKG $(1133,1 \mathrm{~mL} /$ hari). Anak prasekolah berusia $\geq 54$ bulan dan anak yang tinggal di area rural lebih berisiko mengalami kekurangan asupan minum dibandingkan anak yang berusia muda serta tinggal di daerah urban.

\section{Ucapan terima kasih}

Ucapan terima kasih diberikan kepada para tim peneliti dan penulis naskah atas partisipasinya dalam proses penulisan artikel. Terima kasih kami sampaikan kepada dr. Aida Riyanti, SpOG(K), M.Sc, dr. Shanty Olivia Jasirwan, SpOG, dr. Rina Agustina, MSc, PhD, dr. Purwita Wijaya Laksmi, SpPD(K), Puji 
Titis Prawitasari dkk: Profil asupan minum pada anak prasekolah di daerah urban dan rural

Lestari, S.Gz, M.Gizi, Nisrina Hanisa, S.Gz, M.Gizi, Ahmad Thohir Hidayat, S.Gz, M.Gizi, Ulil Albab, S.Gz. Putri Novia Choiri Insani, S.Gz, M.Si.

\section{Daftar pustaka}

1. Amstrong LE. Rationale for renewed emphasis on dietary water intake. Proceeding the 1st Annual Scientific Meeting on Hydration for Health. Hydration for Health. 2010;7-8.

2. Bottin JH, Morin C, Guelinckx I, Perrier ET. Hydration in Children: What do we know and why does it matter? Ann Nutr Metab 2019;74 Suppl 3:11-8.

3. Sontrop JM, Dixon SN, Garg AX, Buendia- Jimenez I, Dohein O, Huang SH, Clark WF. Association between water intake, chronic kidney disease, and cardiovascular disease: a crosssectional analysis of NHANES data. Am J Nephrol 2013;37: 434-42.

4. Drewnowski A, Rehm CD, Constant F. Water and beverage consumption among children age 4-13y in the United States: Analyses of 2005- 2010 NHANES data. Nutr J 2013;12:1-9.

5. Sleddens EFC, Kremers SPJ, Stafleu A, Dagnelie PC, De Vries NK, Thijs C. Food parenting practices and child dietary behavior. Prospective relations and the moderating role of general parenting. Appetite 2014;79:42-50.

6. Kavouras SA, Arnaoutis G, Makrillos M, dkk. Educational intervention on water intake improves hydration status and enhances exercise performance in athletic youth. Scand J Med Sci Sports 2011;22:684-9.

7. Pross N, Demazières A, Girard N, dkk. Influence of progressive fluid restriction on mood and physiological markers of dehydration in women. Br J Nutr 2013;109:313-21.

8. Bardosono S, Monrozier R, Permadhi I, Manikam NRM, Pohan R, Guelinckx I. Total fluid intake assessed with a 7-day fluid record versus a 24-h dietary recall: a crossover study in Indonesian adolescents and adults. Eur J Nutr 2015;54:17-25.

9. Gandy J. First findings of the United Kingdom fluid intake study. Nutr Today 2012;47:14-6.

10. Gandy J. Water intake: validity of population assessment and recommendations. Eur J Nutr 2015;54:S11-6.

11. Pinket AS, De Craemer M, Maes L, dkk. Water intake and beverage consumption of pre- schoolers from six European countries and associations with socio-economic status: The ToyBox-study. Public Health Nutr 2016;19: 2315-25.

12. Laksmi PW, Morin C, Gandy J, dkk. Fluid intake of children, adolescents and adults in Indonesia: results of the
2016 Liq.In7 national cross-sectional survey. Eur J Nutr 2018;57:89- 100 .

13. Brooks CJ, Gortmaker SL, Long MW, Cradock AL, Kenney EL. Racial/ethnic and socioeconomic disparities in hydration status among US adults and the role of tap water and other beverage intake. Am J Public Health 2017;107:1387-94.

14. Briawan D, Rachma P, Annisa K. Kebiasaan konsumsi minum dan asupan cairan pada anak usia sekolah di perkotaan. J Gizi Pangan 2011;6:186-91.

15. Central Bureau of Statistic. Distribusi dan Kepadatan Penduduk Menurut Kabupaten/Kota di Provinsi DKI Jakarta, 2015. Diakses pada 1 September 2020. Didapat dari: https:// jakarta.bps.go.id/statictable/2017/01/30/1 38/distribusi-dankepadatan-penduduk-menurut- kabupaten-kota-di-provinsidki-jakarta-2015.html.

16. Central Bureau of Statistic. Proyeksi penduduk Maluku Menurut Kabupaten/Kota, 2010-2020. Diakses pada 1 September 2020. Didapat dari: https://maluku.bps.go.id/ dynamictable/2019/06/14/291/proyeksi-penduduk-malukumenurut-kabupaten-kota-2010-2020.html.

17. BAPPEDA Provinsi Maluku. Tabel luas wilayah menurut Kabupaten di Maluku. Diakses pada 1 September 2020. Didapat dari: https://maluku.bps.go.id/statictable/2015/03/24/3/ luas-wilayah-menurut-kabupaten-km2-.html. Diakses pada 1 September 2020.

18. Kemenkes RI. Angka Kecukupan Gizi yang dianjurkan untuk masyarakat Indonesia. Jakarta: Kemenkes RI; 2019.

19. Iglesia I, Guelinckx I, De Miguel-Etayo PM, dkk. Total fluid intake of children and adolescents: cross-sectional surveys in 13 countries worldwide. Eur J Nutr 2015;54:57-67.

20. Franse CB, Wang L, Constant F, Fries LR, Raat H. Factors associated with water consumption among children: a systematic review. Int J Behav Nutr Phys Act 2019;16:64-8.

21. Zheng M, Rangan A, Olsen NJ, dkk. Substituting sugarsweetened beverages with water or milk is inversely associated with body fatness development from childhood to adolescence. Nutrition 2015;31:38-44.

22. Irwin LG. Siddiqi A, Hertzman C. Early child development: a powerful equalizer. Vancouver: Human Early Learning Partnership; 2007.

23. Adams EA, Boateng GO, Amoyaw JA. Socioeconomic and demographic predictors of potable water and sanitation access in Ghana. Soc Indic Res 2016;126:673-87.

24. Irianti S, Prasetyoputra P, Sasimartoyo TP, Determinants of household drinking-water source in Indonesia: An analysis of the 2007 Indonesian family life survey. Cogent Medicine 2016; 3:115-43.

25. Atipoka FA, Water supply challenges in rural Ghana. Desalination 2009;248:212-20. 